\title{
Protective Effect of Propolisagainst Osteoporosis in Rat Model
}

\author{
Faten K. Abd El Hady ${ }^{a^{*}}$;Mohga S. Abdallah ${ }^{b}$; Rokia A. S. El-Banna ${ }^{c}$; \\ Hatem A. El-Mezayen ${ }^{b}$; Safinaz S. EI Din Sayed ${ }^{d}$; Laila S. Ibrahim ${ }^{a}$ \\ ${ }^{a}$ Department of Chemistry of Natural Products, National Research Center, \\ Egypt,* fatenkamal@hotmail.com. ; ${ }^{\mathbf{b}}$ Department of Chemistry \\ (Biochemistry devision), Faculty of Science, Helwan University; \\ ${ }^{\mathbf{c}}$ Department of Biological Anthropology, National Research Center, Egypt; \\ ${ }^{d}$ Department of Histology, Faculty of Medicine, Cairo University
}

\begin{abstract}
Osteoporosis is a global problem that affects adversely the post-menopausal women and elderly men as well. It is defined as a systemic skeletal disease characterized by low bone mass and microarchitectural deterioration of bone tissue, leading to enhanced bone fragility and consequent increase in fracture risk. The present study aimed to evaluate the effect of Egyptian propolis in the prevention of osteoporosis induced by ovariectomy (OVX) in rats. The biochemical, bone mineral density (BMD), histopathological, morphometric and scanning electron microscopic (SEM) analyses of treated animals were performed. The increase in BMD, serum calcium (Ca), femur shaft width and decrease in serum osteocalcin, alkaline phosphatase, tartrate-resistant acid phosphatase, urinary Ca levels are higher in rats treated with propolis than those of OVX group, which indicate marked restorative action. SEM study revealed porous and erosive appearance of femur bone at the epiphyseal region, shaft and head in the OVX rats when compared with sham operated rats. Treatment with propolis decreased the resorption and maintained the intactness andintegrity of the femur surface indicating its usefulness in the prevention of bone loss.

Key Words: Osteoporosis, Ovariectomy, Propolis, BMD, SEM

Abbreviations: OVX, ovariectomized rats; BMD, bone mineral density; OC, osteocalcin; ALP, alkaline

phosphatase; TRAP, tartrate-resistant acid phosphatase; SEM, Scanning Electron Microscopy; Ca, calcium.

\section{INTRODUCTION}

Osteoporosis is a metabolic bone disease characterized by a defect in bone mineralization. After age 40, a slow process of bone loss begins in both sexes and continues until late of life. In women after menopause,

there is an accelerating rate of bone loss because of the decreasing estrogen secretion associated with aging ${ }^{1}$.Hormone replacement therapy (HRT) has been established as a regime for prevention of postmenopausal bone loss ${ }^{2}$. However,recent evidence indicates
\end{abstract}


that its long-term use is accompanied by side effects, such as increased risk of breast, ovarian and endometrial cancer $^{3}$.

Bisphosphonates are currently the major drugs used to treat osteoporosis. However, they are associated with side effects as esophageal cancer and osteonecrosis of the jaw ${ }^{4}$. Thus, alternative means of proven efficacy and safety should be developed for prevention and treatment of postmenopausal osteoporosis.

The polyphenolic compounds (flavonoids and phenolic acids) have received some attention for their potential role in preventing osteoporosis ${ }^{5}$.Also, flavonoids have been characterized as selective estrogen receptor modulators with similar beneficial effects to raloxifene on bone ${ }^{6}$.Flavonoids have been shown to inhibit bone loss in rats, both by slowing resorption and by increasing osteoblastic activity, resulting in increased bone strength ${ }^{7}$.

Propolis is a resinous substance collected by the bees from various tree buds. Propolis composition is directly related to that of bud exudates collected by bees from various trees. Propolis has attracted researchers' interest in the last decades because of several biological properties, such asimmunomodulatory, antitumor, antimicrobial,antiinflammatory, antioxidant, among others. More than 300 constituents have been identified in different propolis samples ${ }^{\mathbf{8}}$. Flavonoids, aromatic acids, terpenoids, steroids and phenolic compounds appear to be the principal components responsible for the biological activities of propolis ${ }^{\mathbf{9 , 1 0}}$.The potential estrogenic activity of propolis was investigated in vitro using the MCF-7 human breast cancer cell proliferation ${ }^{\mathbf{1 1}}$, human estrogen receptor binding and yeast-based steroid receptor transcription, and in vivo using the immature rat uterotrophic effect ${ }^{12}$.

The aim of the present study was to evaluate the effect of Egyptian propolis in prevention of osteoporosis induced by ovariectomy in rats (an established model for postmenopausal osteoporosis ${ }^{13}$.To our knowledge, the present study is the first research of the protective effects of propolis against high bone turnover, loss of bone $\mathrm{Ca}$ and reduced $\mathrm{Ca}$ retention associated with estrogen deficiency in OVX animals.

\section{MATERIALS \& METHODS}

This study was supported by National Research Centre Cairo Egypt [project No. 2/3/5].

Propolis: Propolis was collected from Gharbia province of east area of Nile Delta, Egypt. The sample was collected during March 2010.

Propolis Extraction and Sample Preparation for HPLC:One $g$ propolis was cut into small pieces and extracted at room temperature with $50 \mathrm{ml}$ of $70 \%$ ethanol (twice after 24 hours). The alcoholic extract was evaporated under vacuum at 50 ${ }^{\circ} \mathrm{C}$ until dryness. The dry extract was dissolved in methanol and filtered through a $0.45-\mu \mathrm{m}$ filter before HPLC analysis.

HPLC Analysis of Propolis Polyphenolics: The HPLC analysis was achievedwith Agilent 1100 
seriesliquid chromatography with UV detector and an auto- sampler, the method was mentioned previously $^{10,14}$.

Polyphenolics Identification and Quantification: Polyphenolics were identified by chromatographic comparisons with authentic samples. Response factors for the authentic samples and the concentration of polyphenolics in propolis sample was calculated ${ }^{15}$.

Preparation of propolis extract: Propolis $70 \%$ ethanol extract was freshly prepared; solvent was evaporated under reduced pressure to a syrupy form.

Acute toxicity (OECD guidelines 425 adoption):Twenty healthy Wistar albino rats of either sex were randomly divided into two groups of equal size. Animals of both groups were fasted overnight before the test. The first group was given 5000 $\mathrm{mg} / \mathrm{kg}$ body weight of freshly prepared ethanol extract of propoliswhile the other group was given an equivolume of saline. The animals were observed immediately and then after $30 \mathrm{~min}, 1,2,4,6 \mathrm{~h}$ and thereafter daily for 14 days. At the end of the fourteenth day the animals were sacrificed with excess ether anaesthesia and dissected for examination of vital organs.

Ethics: The study followed the regulations of Medical Research Ethics Committee, National Research Center, Egypt (i.e., Rules for the Care and Use of Laboratory Animals, no. 10-132).

Animals: Wister female albino rats (150-160 g)from National Research Center animal house (Egypt) were used in the current study. Rats were fed a casein based diet prepared according to the AIN-93M $\operatorname{diet}^{16)}$,(Table 1)and water ad libitum. The environmental conditions were standardized with respect to temperature, humidity and light.

Table 1: Composition of casein based diet (AIN-93M diet)

\begin{tabular}{|c|c|c|c|}
\hline $\begin{array}{c}\text { Ingredients Casein } \\
\text { based diet }\end{array}$ & $\begin{array}{l}\text { (g/kg } \\
\text { diet) }\end{array}$ & Ingredients Casein based diet & $\begin{array}{l}\text { (g/kg } \\
\text { diet) }\end{array}$ \\
\hline Corn starch & 620.692 & Mineral mixture (AIN-93M-MX) & 35 \\
\hline Casein $(85 \%$ protein $)$ & 140 & Vitamin mixture (AIN-93M-VX) & 10 \\
\hline Sucrose & 100 & L-cystine & 1.8 \\
\hline *Corn oil & 40 & Choline chloride & 2.5 \\
\hline Fiber & 50 & Ter-butylhydroquinone & 0.008 \\
\hline
\end{tabular}

*Corn oil was used instead of soybean oil to eliminate any possible interference with isoflavones in soybeanoil.

Animal Experiment: After two weeks of acclimatization, the rats were anaesthetizedwith sodium pentobarbitone $(35 \mathrm{mg} / \mathrm{kg}$, i.p.), and bilateralovariectomy was done
aseptically(OVX). Sham operation (group $\mathrm{I}, \mathrm{n}=6$ ) wasdone in the same manner but only exposing the ovaries.The animals were given prophylactic ampicillin (4000 IU/kg, 
i.p.) for 3 days and coloplast paste (Humlebaek, Denmark)applied locally. After 24 weeks, the OVX rats were randomly divided into fourgroups and orally treated with $\mathrm{H}_{2} \mathrm{O}$ (OVXgroup II) and400 mg propolis / kg (group III)as daily dose for 9 weeks. The shamoperatedgroup (I) was orally treated with $\mathrm{H}_{2} \mathrm{O}$. The body weight ofeach animal was determined once a week until the final dayof administration.

Serum Chemistry: Serum calcium (Ca), phosphorus (P), magnesium $(\mathrm{Mg})$, alkaline phosphatase (ALP) and tartrate-resistant acid phosphatase (TRAP)concentrations were measured by standard colorimetric methods using kits from BioDiagnostic (Cairo, Egypt). Serum Osteocalcin (OC) was measured using an enzyme linked immune sorbent assay (ELISA) kit specific for ratOC (Biomedical Technology, Staughton, IN, USA).

Urine Chemistry: Urine $\mathrm{Ca}, \mathrm{P}$ and creatinine $(\mathrm{Cr})$ values were analyzed by the same method used for the serum samples.

Measurement of bone mineral content (BMC) and bone mineral density (BMD): The BMC and BMD were made at the proximal, distal and total femur by dual energy X-ray absorptiometry PIXImus (GE Lunar Co, Wisconsin, USA).

Histopathological Studies ofBone Histopathological analysis was carried out on femur of rats. After the rats were sacrificed the right femurs were removed, dissected free of soft tissue and fixed in $10 \%$ buffered formal saline. The specimens were then decalcified in EDTA solution for $10-14$ days at $5^{\circ} \mathrm{C}$. Tissues were dehydrated in graded alcohols and embedded in paraffin. $5 \mu \mathrm{m}$ sections were cut and stained with hematoxylin and eosin $(\mathrm{H} \& \mathrm{E})$ for morphological study ${ }^{17}$.

Morphometric Measurement: Quantitative analysis measurement was achieved by using computerized image analyzer (Leica Qwin 500 image). The thickness of the shaft of the femur was measured in longitudinal sections of all groups (10 fields per section at power magnification $x$ 40). Mean shaft thickness for each group was obtained and subjected for statistical analysis.

Scanning Electron Microscopy (SEM) The frozen femurs were placed in 5\% sodium hypochlorite solution (Commercial Bleach) for 4 $\mathrm{h}$. The bones were then dehydrated in ethanol and dried, mounted on stubs and coated with gold using a sputter coater. ${ }^{18)}$ The bones were examined on JEOL JXA-840A electron Probe Microanalyzer, for the observation of qualitative bone resorption at the epiphyseal edges, shaft and head of femur.

Statistical analysis: The data was analyzed using one way ANOVA followed by post hoc Sheffe's Test using SPSS computer software Version 7.5. Level of significance was measured at 0.05 and 0.01.t paired test was used for the analysis of weekly weight gain.

\section{RESULTS}

HPLC Quantitative Analysis of
PropolisPolyphenolics:
Thepolyphenolics present in propolissamplewas studied by HPLC 
analysis. A total of 27 compounds were detected in propolis sample, from which 3 isoflavones (formonontin, genistein, prunetin) were identified. Naringenin, quercetin-3,3'-dimethylether and pinocembrin were highly detected in propolis sample (Table 2).

Table 2.HPLC Quantitative Analysis of PropolisPolyphenolics

\begin{tabular}{|l|l|l|l|l|l|l|l|l|}
\hline No & Name & $\begin{array}{l}\mathrm{mg} / \mathrm{g} \\
\text { propolis }\end{array}$ & No & Name & $\begin{array}{l}\mathrm{mg} / \mathrm{g} \\
\text { propolis }\end{array}$ & No & Name & $\begin{array}{l}\mathrm{mg} / \mathrm{g} \\
\text { propolis }\end{array}$ \\
\hline 1) & $\begin{array}{l}\text { Hydrocinnamic } \\
\text { acid }\end{array}$ & 18.1 & $10)$ & $\begin{array}{l}\text { Quercetin-7- } \\
\text { methylether }\end{array}$ & 4.6 & $19)$ & Hesperetin & 3.9 \\
\hline 2) & $\begin{array}{l}\text { Hydrocaffeic } \\
\text { acid }\end{array}$ & 15.7 & $11)$ & $\begin{array}{l}\text { Dimethylallyl } \\
\text { caffeate }\end{array}$ & 2.4 & $20)$ & $\begin{array}{l}\text { 8-Methoxy- } \\
\text { kaempferol }\end{array}$ & 0.75 \\
\hline 3$)$ & $\begin{array}{l}\text { Coniferyl } \\
\text { alcohol }\end{array}$ & 2.8 & $12)$ & Pinocembrin & 39.4 & $21)$ & Apigenin & 1.02 \\
\hline 4$)$ & Caffeic acid & 1.6 & $13)$ & Luteolin & 3.7 & $22)$ & $\begin{array}{l}\text { Luteolin-3'- } \\
\text { methylether }\end{array}$ & 5.4 \\
\hline 5$)$ & Eriodictyol & 4.7 & $14)$ & Quercetin & 1.4 & $23)$ & Prunetin & 3.0 \\
\hline 6$)$ & Liquiriteginin & 2.0 & $15)$ & Naringenin & 14.5 & $24)$ & Formononetin & 1.8 \\
\hline 7$)$ & Myricetin & 5.6 & $16)$ & Pinobankasin & 0.83 & $25)$ & Acacetin & 7.0 \\
\hline 8$)$ & $\begin{array}{l}\text { Quercetin-3,3'- } \\
\text { dimethylether }\end{array}$ & 22.8 & $17)$ & $\begin{array}{l}\text { Quercetin-3- } \\
\text { methylether }\end{array}$ & 1.3 & $26)$ & Biochanin A & 10.2 \\
\hline 9$)$ & Formonontin & 10.1 & $18)$ & Genistein & 1.9 & $27)$ & Pinostrobin & 1.2 \\
\hline & & & & & & & Total & 187.7 \\
\hline
\end{tabular}

Animal Weight: The results of the present study indicate that body weight gain was higher in OVX group than that in sham group $(\mathrm{p}<0.01)$. The weight gain for the OVX rats with control diet was not statistically different from the OVX treated group (Table 3).

Table 3. Body weight of sham group,ovariectomized group andPropolisgroup.

\begin{tabular}{|l|l|l|l|}
\hline & Week 0 & Week 24 & Week 33 \\
\hline Sham & $121.50 \pm 0.38$ & $232.23 \pm 0.48^{\mathbf{b , d}}$ & $245.10 \pm 0.14^{\mathbf{b , d}}$ \\
\hline OVX & $121.08 \pm 0.61$ & $305.78 \pm 0.27^{\mathbf{a , c}}$ & $310.70 \pm 0.25^{\mathbf{a , c}}$ \\
\hline Propolis & $120.95 \pm 0.17$ & $307.97 \pm 0.17^{\mathbf{a , c}}$ & $309.05 \pm 0.16^{\mathbf{a , c}}$ \\
\hline
\end{tabular}

Values are given as mean \pm SE for six rat in each group. a, significant difference at $P$

$<0.05$ compared to sham; $\boldsymbol{b}$, significant difference at $P<0.05$ compared to ovx; $\boldsymbol{c}$, significant difference at $P<0.01$ compared to sham.; $\boldsymbol{d}$, significant difference at $P<$ 0.01compared to ovx. 
Serum Chemistry: The serum alkaline phosphatase (ALP), tartrateresistant acid phosphatase (TRAP) and osteocalcin (OC) activity of sham, OVX and OVX treated group are shown in Table 4. Rats of OVX group showed a significant increase in serum ALP, TRAP and OC activity when compared to animals of sham group, $\mathrm{P}<0.01$. This increase was significantly lowered $(\mathrm{P}<0.01)$ in OVX treated group. Likewise, the significant decrease in serum calcium $(\mathrm{Ca})$, phosphorus $(\mathrm{P})$ and magnesium $(\mathrm{Mg})$, in ovariectomized animals, compared to sham, was effectively increased in rats on OVX treated group ( $\mathrm{P}<0.05)$, Table 4.

Urine Chemistry: The urinary calcium, phosphorus and creatinineconcentration together with $\mathrm{Ca}: \mathrm{Cr}$ ratio of sham group, ovariectomized and propolis treated group are shown in Table 5 . Compared with the sham-operated group, OVX animals showed a significant increase in all the urinary parameters studied. Elevated responses of all these parameters were significantly decreased in treated group at $\mathrm{P}<0.01$.

Table 4: The serum alkaline phosphatase (ALP), tartrate-resistant acid phosphatase (TRAP), osteocalcin (OC), calcium (Ca), phosphorus (P) and magnesium (Mg)concentration in the different studied groups.

\begin{tabular}{|l|l|l|l|}
\hline parameter & \multicolumn{1}{c|}{ Sham } & \multicolumn{1}{c|}{ OVX } & \multicolumn{1}{c|}{ Propolis } \\
\hline ALP (U/l) & $15 \wedge .42 \pm 15.87^{\mathbf{b , d}}$ & $275.14 \pm 3.35^{\mathbf{a}, \mathbf{c}}$ & $156.14 \pm 11.27^{\mathbf{b , d}}$ \\
\hline TRAP (U/l) & $48.99 \pm 0.866^{\mathbf{b , d}}$ & $61.9 \pm 0.50^{\mathbf{a , c}}$ & $40.8 \pm 1.43^{\mathbf{a , b , d}}$ \\
\hline OC (ng/ml) & $0.55 \pm 0.18^{\mathbf{b , d}}$ & $3.1 \pm 0.71^{\mathbf{a , c}}$ & $0.45 \pm 0.08^{\mathbf{b , d}}$ \\
\hline Ca (mg/dl) & $9.70 \pm 1.59^{\mathbf{b , d}}$ & $8.72 \pm 1.43^{\mathbf{a , c}}$ & $9.11 \pm 1.49^{\mathbf{a}, \mathbf{b}, \mathbf{c}}$ \\
\hline P (mg/dl) & $5.74 \pm 0.11$ & $5.4 \pm 0.13$ & $6.01 \pm 0.07^{\mathbf{b , d}}$ \\
\hline Mg (mg/dl) & $2.53 \pm 0.41^{\mathbf{b}}$ & $2.38 \pm 0.38^{\mathbf{a}}$ & $2.44 \pm 0.38$ \\
\hline
\end{tabular}

Values are given as mean \pm SE for six rat in each group. a, significant difference at $P$ $<0.05$ compared to sham; $\boldsymbol{b}$, significant difference at $P<0.05$ compared to ovx; $\boldsymbol{c}$, significant difference at $P<0.01$ compared to sham.; $d$, significant difference at $P$ $<0.01$ compared to ovx.

Table5. UrinaryCa, P, and creatinine excretion values in the different studied groups.

\begin{tabular}{|l|l|l|l|}
\hline & \multicolumn{1}{|c|}{ SHAM } & \multicolumn{1}{c|}{ OVX } & \multicolumn{1}{c|}{ Propolis } \\
\hline $\mathbf{C a}(\mathbf{m g} / \mathbf{2 4} \mathbf{~ h})$ & $0.078 \pm 0.049^{\mathbf{b , d}}$ & $0.47 \pm 0.105^{\mathbf{a , c}}$ & $0.081 \pm 0.018^{\mathbf{a , b , c , d}}$ \\
\hline $\mathbf{P} \mathbf{( m g / 2 4} \mathbf{~ h})$ & $0.54 \pm 1.83^{\mathbf{b , d}}$ & $0.931 \pm 1.07^{\mathbf{a , c}}$ & $0.825 \pm 1.61^{\mathbf{a}, \mathbf{b}, \mathbf{c}, \mathbf{d}}$ \\
\hline $\mathbf{C r} \mathbf{( m g / 2 4} \mathbf{~ h})$ & $0.28 \pm 0.48^{\mathbf{b , d}}$ & $0.532 \pm 2.041^{\mathbf{a , c}}$ & $0.360 \pm 0.06^{\mathbf{a , b , c , d}}$ \\
\hline $\mathbf{C a} / \mathbf{C r}$ ratio & $0.28 \pm 0.005^{\mathbf{b , d}}$ & $0.883 \pm 0.005^{\mathbf{a , c}}$ & $0.225 \pm 0.001^{\mathbf{b , d}}$ \\
\hline
\end{tabular}

Values are given as mean \pm SE for six rat in each group. a, significant difference at $P$ $<0.05$ compared to sham; $\boldsymbol{b}$, significant difference at $P<0.05$ compared to ovx; $\boldsymbol{c}$, significant difference at $P<0.01$ compared to sham.; $d$, significant difference at $P$ $<0.01$ compared to ovx. 
Table 6: Bone mineral content $(\mathrm{g})$, bone mineral density $\left(\mathrm{g} / \mathrm{cm}^{2}\right)$ in proximal, distal and total regions for femur in the different studied groups.

\begin{tabular}{|c|c|c|c|}
\hline \multirow{2}{*}{ Parameters } & \multicolumn{3}{|l|}{ GROUPS } \\
\hline & SHAM & OVX & Propolis (P) \\
\hline BMD (Proximal) & $0.113 \pm 0.012^{\mathbf{b , d}}$ & $0.104 \pm 0.015^{\mathbf{a}, \mathbf{c}}$ & $0.122 \pm 0.09^{\mathbf{a}, \mathbf{b}, \mathbf{c}, \mathbf{d}}$ \\
\hline BMC( proximal) & $0.094 \pm 0.004^{\mathbf{b , d}}$ & $0.072 \pm 0.036^{\mathbf{a , c}}$ & $0.090 \pm 0.039^{\mathbf{a}, \mathbf{b}, \mathbf{c}, \mathbf{d}}$ \\
\hline BMD ( Distal ) & $0.106 \pm 0.046^{\mathbf{b , d}}$ & $0.099 \pm 0.028^{\mathrm{a}, \mathrm{c}}$ & $0.115 \pm 0.037^{\mathbf{a}, \mathbf{b}, \mathbf{c}}$ \\
\hline BMC( Distal ) & $0.103 \pm 0.009^{\mathbf{b , d}}$ & $0.056 \pm 0.032^{\mathrm{a}, \mathrm{c}}$ & $0.093 \pm 0.033^{\mathbf{a}, \mathbf{b}, \mathbf{c}, \mathbf{d}}$ \\
\hline BMD (Total) & $0.119 \pm 0.003^{\mathbf{b , d}}$ & $0.105 \pm 0.005^{\mathbf{a , c}}$ & $0.125 \pm 0.058^{\mathbf{a}, \mathbf{b}, \mathbf{c}, \mathbf{d}}$ \\
\hline BMC (Total) & $0.256 \pm 0.021^{\mathbf{b , d}}$ & $0.188 \pm 0.092^{\mathbf{a}, \mathbf{c}}$ & $0.279 \pm 0.012^{\mathbf{a}, \mathbf{b}, \mathbf{c}, \mathbf{d}}$ \\
\hline
\end{tabular}

Values are given as mean \pm SE for six rat in each group. a, significant difference at $P$ $<0.05$ compared to sham; $\boldsymbol{b}$, significant difference at $P<0.05$ compared to ovx; $\boldsymbol{c}$, significant difference at $P<0.01$ compared to sham.; $d$, significant difference at $P$ $<0.01$ compared to ovx.

BMC and BMD: Animals in the OVX group had significantly lower density and content of the proximal, distal and total femur $(\mathrm{P}<0.01)$ compared with the sham group. propolis group was seen to recover the density of right femur bones significantly, $(\mathrm{P}<0.01)$ (Table 6).

Histopathological Studies in Bone: The histopathological sections of the middle shaft of the femur bone of a sham group showed the normal architecture of the bone tissue (Fig. 1 A). The ovariectomized group shows irregular resorption areas under the endostium and under the periostium(Fig. 1 B). Examination of the middle shaft of the femur bone of a rat treated with propolis extract showed improvement of bone tissue architecture in the form of regularity of both inner and outer surfaces of the bone tissue although the Haversian canals are still widened (Fig. 1C).
Morphometric results: The femur shaft of animals in the sham group showed a mean total thickness $643.18 \mu \mathrm{m}$, in the ovariectomized group the thickness decreased to $203.08 \mu \mathrm{m}$. With propolis treatment, the shaft thickness returned more or less back near to the sham group value $(501.24 \mu \mathrm{m})(\mathrm{P}<0.01)$, (Fig. 2). Scanning electron microscopy: The epiphyseal edges of the distal part of the femur bone, its shaft and head were observed to study the resorption pattern in all groups. Extensive resorption was detected in ovariectomized animals (Fig.3; b1,b2 and b3) when compared with sham operated animals in which the bony surfaces lacked any resorption pits (Fig.3; a1,a2 and a3). In propolis group the surfaces of the epiphyseal edges, the shaft and the head of the femur were almost similar to the sham group (Fig.3; c1,c2 and c3). 

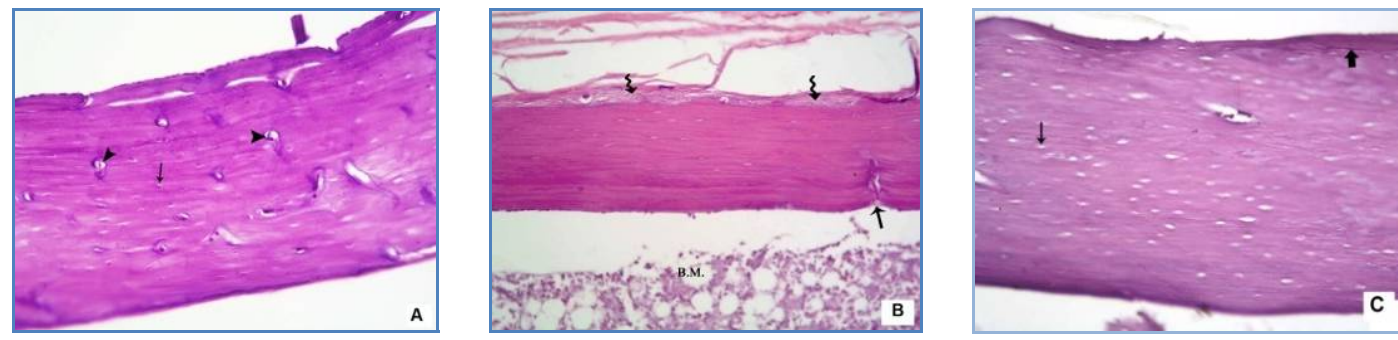

Fig. 1: Photomicrographs of a longitudinal section in the shaft of the femurs of a female albino rat, A: of the shamgroup showing Volkmann's canals (arrow head) and osteocytes inside their lacunae (arrow). B: of the ovariectomized group showing irregular resorption areas under the endostium (arrow) and under the periostium (zigzag arrow). Note the medullary cavity with the bone marrow inside (B.M.). C: of the propolis group, normal bone architecture is noted; cement lines can be seen (thick arrow) with no separation of the bone lamellae. The osteocytes are seen inside their lacunae (thin arrow).

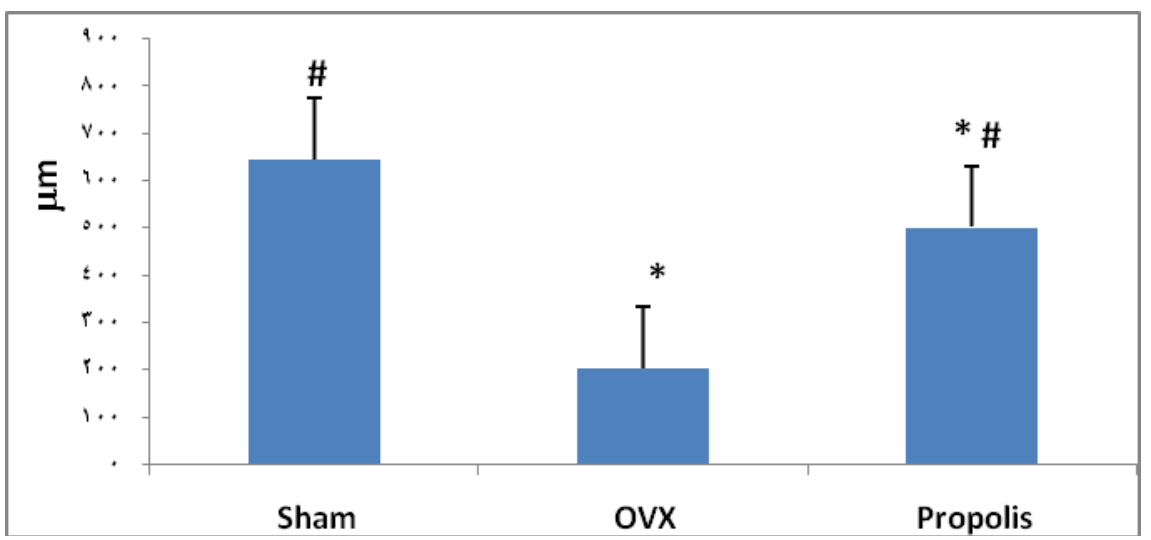

Fig. 2: The thickness of the shaft of the femur of all groups. Values are given as mean \pm SE for six rats in each group.*, Significant difference at $\mathrm{P}<0.01$ compared to Sham group. \#, significant difference at $\mathrm{P}<0.01$ compared to OVX group. 

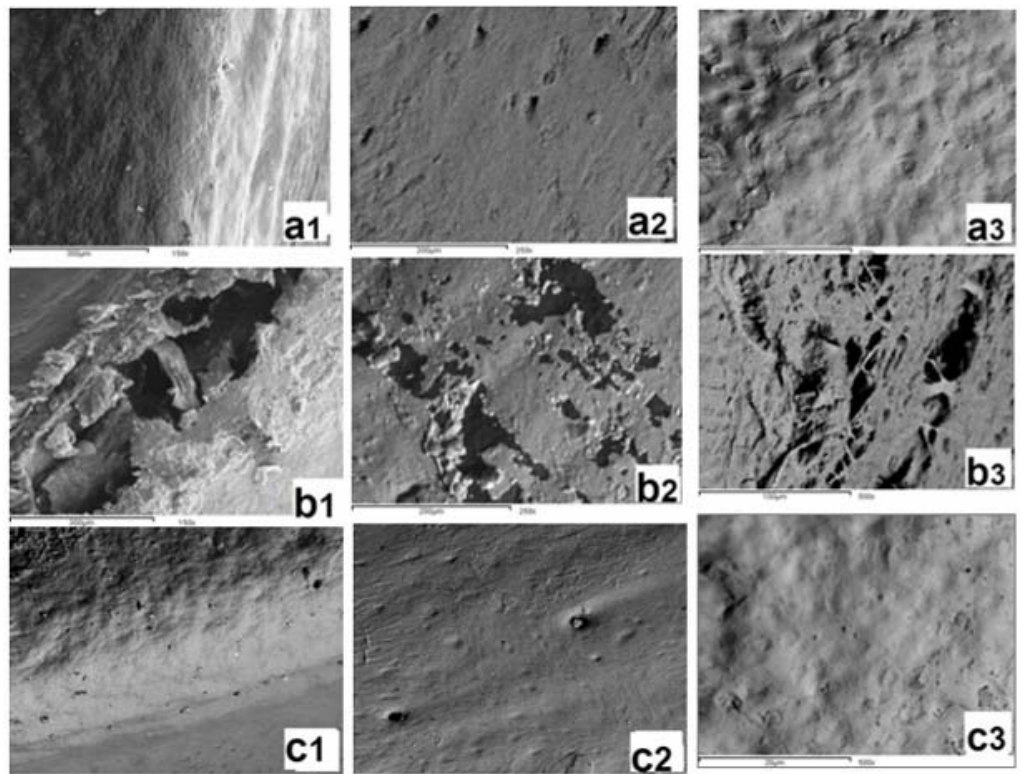

Fig. 3: Scanning electron photomicrographs (150X) demonstrating resorptive surface in remodeling sites at the epiphyseal edges of femur from rats of sham operated (a1), Ovariectomized (b1) and propolis group (c1). Scanning electron photomicrographs for Shaft $(\mathbf{a} 2, \mathbf{b 2} \& \mathbf{c 2}, 250 \mathrm{X})$ and for femur head $(\mathbf{a 3}, \mathbf{b 3} \& \mathbf{c} 3,500 \mathrm{X})$. Note the increased number of resorption pits in OVX group compared with sham and treated groups.

\section{DISCUSSION}

Ovarian hormone deficiency associated osteoporosis following menopause is the most common cause of age-related bone loss. This disorder is characterized by reduced amount of bone leading to diminished physical strength of the skeleton and an increased susceptibility to fracture 5 .

Phytoestrogens are a group of biologically active plant substances with a chemical structure similar to that of estradiol, an endogenous estrogen. This structural similarity accounts for the ability of these compounds to bind to estrogen receptors (ERs) and exert various estrogenic or antiestrogenic effects ${ }^{19}$.

To our knowledge, the present study is the first demonstration of the protective effects of propolis extract against high bone turnover, loss of bone $\mathrm{Ca}$ and reduced $\mathrm{Ca}$ retention associated with estrogen deficiency in OVX animals.

As expected, OVX animals in the present study exhibited all the characteristics associated with estrogen deficiency, such as weight gain, negative calcium balance, high bone turnover and uterine atrophy ${ }^{13}$.

The results of this study indicate that body weight gain was higher in OVX group than in sham group 
$(\mathrm{p}<0.01)$ and the weight gain for the OVX rats was not different from that of propolis treated group; a positive association between bone density and body weight has been well documented $^{20}$. It also was devoid of any uterotrophic activity because uterine weight was not different in OVX and propolis treated group (data not shown). The results suggest that propolis extract at the given dose did not behave like estrogen in the regulation of body weight and uterine tissue growth in the OVX rats.

The serum activity of alkaline phosphatase (ALP)and osteocalcin (OC), an index of bone formation ${ }^{21}$, has been reported to be significantly greater in an OVX group than in a sham group. Tartarate-resistant acid phosphatase (TRAP) is released during the bone-resorbing activity of osteoclasts $^{22}$,a similar change was observed in this study. Propolistreatment significantly decreased the activity of serum (ALP, TRAP and OC).

Fasting urinary calcium excretion and calcium to creatinine ratio could also be used as an important variable for estimating net bone resorption. Again, the treatment with propolis reduced the urinary excretion of calcium and calcium to creatinine ratio to a lower level than that of OVX group. Urinary excretion of $\mathrm{Ca}$ was elevated in the OVX rats ${ }^{23}$. Since a rise in serum alkaline phosphatase and the urinary calcium to creatinine ratio have been linked with collagen degradation, bone resorption and osteoporosis $^{24}$.

As expected, OVX resulted in significant decrease in the femur
BMD after 33 weeks. This loss of bone mass was accompanied by a significant increase in bone remodeling, as was evidenced by the increased levels of the bone turnover markers (serum OC, ALP and TRAP). Treatment with propolis prevented the decreases in BMD, which was reflected by the decreases in serum OC, ALP and TRAP levels, indicating a reduction in bone turnover. A decrease in urinary calcium excretion and increase in serum calcium might contribute to the increase in $\mathrm{BMD}^{25}$.

The rate of bone turnover after ovariectomy can be attributed to the absence of estrogen. Estrogen has the ability to decrease the differentiation of the bone resorbing osteoclast progenitor cells ${ }^{\mathbf{2 6}}$, inhibit the bone resorbing activity of terminally differentiated osteoclasts ${ }^{\mathbf{2 5}}$. That is why estrogen deprivation can cause repeated activation of the bone remodeling mechanism and elevate the rate of bone turnover ${ }^{27}$.

The mechanisms by which propolis flavonoids positively affect bone turnover rate may be directly by interacting with estrogen receptors ER- $\beta$. The rat and human ER exists as two subtypes ER $\alpha$ and $\operatorname{ER} \beta$. ER $\beta$ is more abundant than $\mathrm{ER} \alpha$ in bone tissue while $\mathrm{ER} \alpha$ is mainly distributed in reproductive system, especially the breast and uterus. Thus, propolis flavonoids, as naturally occurring Selective Estrogen Receptor Modulators, might show higher affinity for ER $\beta$ than for $\mathrm{ER} \alpha$ that produces optimal action in preventing bone loss without stimulating an unwanted proliferation of the uterine tissues ${ }^{20}$. 
Some sterols have close structural relationship to estradiol and bind to estrogen receptors alpha and beta $^{28}$.In previous studies, propolis contained beside flavonoids, some steroids and terpenoids, which may contribute to this effect ${ }^{\mathbf{1 0}}$. Another possibility would be that the polyphenolic compounds such as flavonoids in propolis extract affect bone, at least in part, through estrogen receptors (ER) as phytoestrogens $\mathrm{do}^{\mathbf{2 6}}$.

Our results were confirmed by histopathologicalexamination of the femurs. Propolis treated group revealed increase in shaft width than that with OVX group, which indicate marked restorative action, thus suggesting that the protective action of the propolistreatment may be due to an increase in bone formation with a reduction in bone resorption.

SEM is used to determine the pattern of bone resorption at the epiphyseal region of distal femur, shaft and head which predominantly contain the areas of bone resorption. Porous and erosive appearance of femur at the epiphyseal edges was more pronounced and prevalent in OVX animals when compared with shamoperated. Treatment with propolis decreased the resorption and maintained the intactness andintegrity of the surface.

\section{CONCLUSION}

The present study clearly demonstrates that daily oral administration of propolis over nine weeks period in the adult OVX rat could ameliorate the estrogen deficiency-induced bone loss in ovariectomized rats.

\section{REFERENCES}

1. Hassan $W N$ and Saed $A M$ (2010): Protective effect of anisefFruit (pimpinella anisum) Against Osteoporosis in Rat Model. Am. J. Biomed. Sci. 2010, x(x), xxx-xxx

2. Prelevic G. M., Kocjan T., Markou A.M. (2005): Hormone replacement therapy in postmenopausal women. Endocrinol., 30, 27-36.

3. Wiseman R. A.(2004): A review of the animal models used to investigate the health benefits of Soy isoflavones. $J$. Clin. Epidemiol., 57, 766-772.

4. Kuehn B.M. (2009): Long-term risks of bisphosphonates probed. JAMA., 301,710-1.

5. Melton, L. (2003): Bring back the acetyls - a novel anticancer movement. Lancet Oncol.4, 710.

6. Brezinski A., Debi A., (1999): Phytoestrogens: the "natural" selective estrogen receptor modulators. Eur.Obste.t Gynecol.Reprod.Bio.l , 85:4751.

7. Horcajada-Molteni M.N., Crespy V., Coxam V., Davicco M.J., Rémésy C., Barlet J.P., (2000): Rutin inhibits ovariectomy-induced osteopenia in rats. J. Bone Miner. Res., 15:2251-2258.

8. Bankova V., (2005): Recent trends and important developments inpropolis research Evidence-based 
Complementary and Alternative Medicinee CAM, 2(1):29-32.

9. Abd El Hady F.K. and A.G. Hegazi (2002): Egyptian propolis: 2- Chemical composition, antiviral and antimicrobial activities of East Nile Delta propolis. Z . Naturforsch. 57c, 386-394.

10. Abd El Hady F. K., Hegazi A.G. and E. Wollenweber E. (2007): Effect of Egyptian propolis on the susceptibility of LDL to oxidative modification and antiviral activitywith special emphasis on chemical composition. Z. Naturforsch62c, 645-655.

11. Abd El-Hady F. K., ElHawary S., Shaker K.H. , Salah N.M. (2010):In vitro cytotoxic effect of Egyptian propolis on human colon, liver, brest and cervix carcenoma cell lines.2nd International Mugla Beekeeping and Pine Honey Congress in Mugla, Turkey, from 5 to 8 October 2010" p 199 - 209.

12. Song YS , Jin C., Jung K.J. , Park E-H, (2002): Estrogenic effects of ethanol and ether extracts of propolis, J. of Ethnopharmacology 82, 89-95.

13. Thompson D.D., Simmons H.A., Pirie C.M., Ke H.Z.,(1995): FDA Guidelines and animal models for osteoporosis.Bone, $17,125 \mathrm{~S}-$ $133 \mathrm{~S}$.

14. Hegazi A. G. and Abd El Hady F. K. (2009): Influence of honey on the suppression of human low density lipoprotein (LDL) Peroxidation In vitro. Evidence-based Complementary and Alternative Medicine (eCAM), 6, 113-121.

15. Ogan K., Katz E. (1981): Liquid chromatographic separation of alkyl phenols withfluorescence and ultra violet detection. Anal Chem, 53,160-3.

16. Reeves, P.G., Nielsen F.H., and Fahey, G.C. Jr. (1993): AIN-93 purified diets for laboratory rodents: Final report of the American Institute of Nutrition and ad hoc writing committee on the reformulation of the AIN76A diet. J. Nutr.123:19391951.

17. Drury, R.A.B. and E.A. Wallington, (1980):

Carleton'sHistochemical

Technique 4th Ed. Oxford, New York, Tononto, Oxford University Press.

18. Miller, S.C., Bowman, B.M. (1998): Comparison of bone loss during normal lactation with estrogen deficiency osteopenia and immobilization osteopenia in the rat. The Anatomical Record 251, 265-274.

19. Usui T., (2006): Pharmaceutical prospects of phytoesterogens. Endocrinol. J., 53,7-20.

20. Ravn P., Cizza G., Bjarnason N.H., Thompson D., Daley M., Wasnich R.D., McClung M., Hosking D., Yates A.J., Christiansen C., (1999); Low body mass. index is an important risk factor for low bone mass and increased bone loss in early postmenopausal women. $J$. Bone Miner. Res. , 14,16221627.

21. Chailurkit LO, Suthutvoravut U, Mahachoklertwattana $P$, 


\section{Charoenkiatkul}

Rajatanavin

R. (2005):

Biochemical markers of bone formation in Thai children and adolescents.Endocr.Res.,31,15969.

22. Li Z., Kong K., Qi W.(2006): Osteoclast and its roles in calcium metabolism and bone development and remodeling. Biochem.Biophys. Res.Commun., 343:345-50.

23. Xie F., Wu C.F., Lai W.P., Yang X.J., Cheung P.Y., Yao X.S., et al.(2005): The osteoprotective effect of Herbaepimedii (HEP) extract in vivo and in vitro. eCAM 2005;2:353-61.

24. Gert B.J., Shao .P, Hanson U.A. et al. (1994): Monitoring bone resorption in early postmenopausal women by an immunoassay for cross-linked collagen peptides in urine. $J$. Bone Miner. Res., 9,135-142.

25. Lerner, U.H. (2006): Bone remodeling in post-menopausal osteoporosis. J. Dent.Res., 85, 584-95.

26. Zava D.T., Dollbaum C.M., Blen M. (1998): Estrogen and progestin bioactivity of foods, herbs and spices. Proc.Soc . Exp. Bio.l Med., 217, 369-378.

27. Nakamura, T., Y. Imai, T. Matsumoto, S. Sato, K. Takeuchi, K. Igarashi, Y. Harada, et al. (2007): Estrogen prevents bone loss via estrogen receptor alpha and induction of Fas-ligand in osteoclasts. Cell., 130, 811-823.

28. Heikkinen A.M., Parviainen M., Niskanen L., et al. (1997): Biochemical bone markers and bone meniral density during postmenopausal hormone replacement therapy with and without vitamin $\quad \mathrm{D}_{3}$ : a prospective, controlled randomized study. J. Clin. Endocrinol. Metab. 82, 24762482. 


\section{التأثير العلاجى لصمغ النحل على نموذج لهشاشة العظام فى حيو انات التجارب التح}

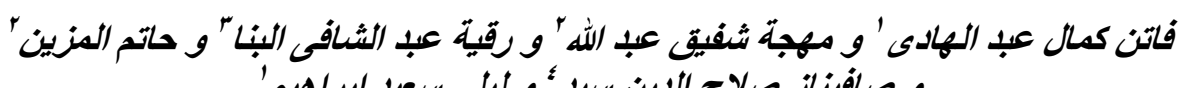

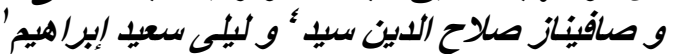

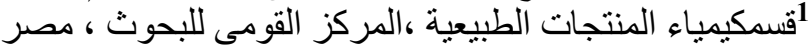

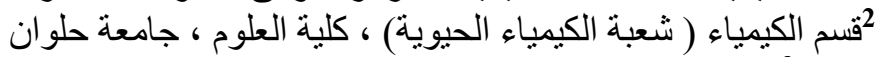

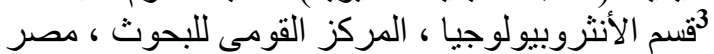

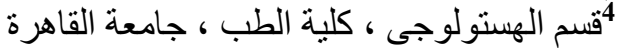

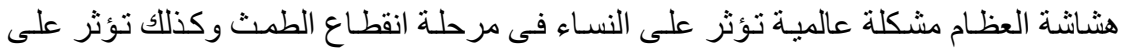

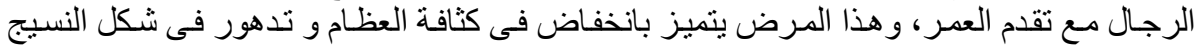

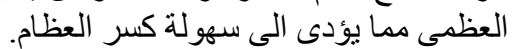

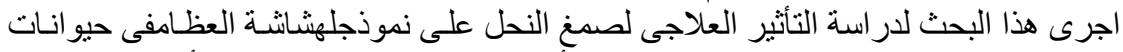

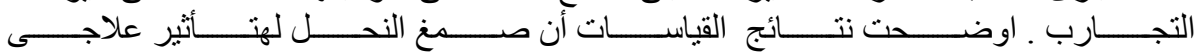

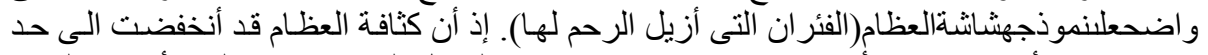

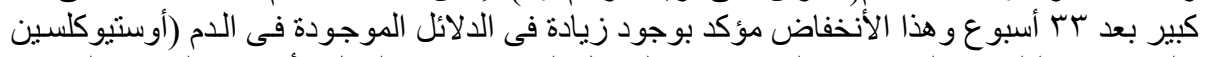

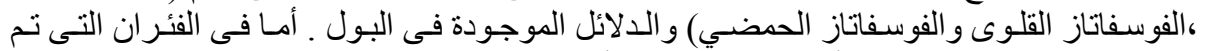

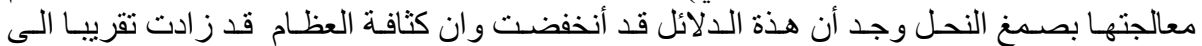

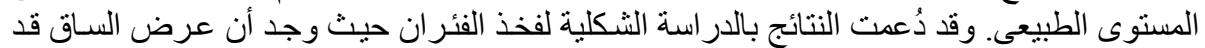

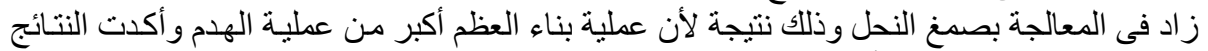

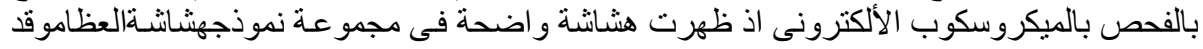

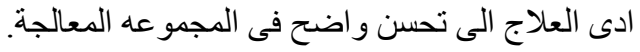

